\title{
A New Apparatus Used to Record the Locomotor Rhythms of Laboratory Reared Prawns and Shrimps
}

\author{
R. Dalley* and H. Bailey \\ Department of Marine Biology, University of Liverpool, Port Erin, Isle of Man, Brìtish Isles
}

\begin{abstract}
A new design of actograph with a high sensitivity is described, employing infra-red emitting diodes and detectors, which can record the movements of small, aquatic animals. The actograph was used to record the locomotory activity of juvenile Palaemon elegans and Crangon crangon reared under LD 12:12, LD 8:8 and LD-Random light/dark cycles. In LD 12:12 both Palaemon elegans and Crangon crangon displayed a daily rhythm, which in Palaemon elegans had a weak endogenous component. In LD 8:8 both species were to an extent synchronized by the light regime, displaying rhythms with an $8 \mathrm{~h}$ or $16 \mathrm{~h}$ component. These rhythms did not persist under constant conditions, and the test animals were also arrhythmic in the LD Random regime. Some specimens of Palaemon elegans which had been reared in LD 8:8 and LD Random, however, displayed weak circadian rhythms under constant conditions.
\end{abstract}

\section{INTRODUCTION}

The small size and translucency of many aquatic crustaceans, makes the automatic recording of their activity difficult. In the absence of suitable techniques, many previous attempts to record locomotor activity in small, aquatic crustaceans have relied solely on direct observations (e.g. Banse, 1964; Morgan, 1965; Jansson and Källander, 1968; Lincoln, 1970; Preece, 1971; Fish and Fish, 1972; Girisch and Dennert, 1975). Those methods which have been tried for recording activity automatically, suffer from a number of inadequacies.

Harris and Wolfe (1955), Enright (1963), Harris (1963), Klapow (1972) and Dieleman (1979), have employed time-lapse photography or time-lapse video T.V. recordings, but the requirement for a light source may be incompatible with any experimental light/dark regime. The thermistor technique of Heusner and Enright (1966) has been reported to record activity successfully in certain small crustaceans (Enright, 1972), but the very fine temperature control required and the impossibility of providing aeration or water circulation, make this system generally impractical. Several attempts have been made to record locomotor activity, using actographs in which the interruption of

\footnotetext{
- Present address: N.E.R.C. Unit, Marine Science Laboratories, Menai Bridge, Gwynedd LL59 5EH, UK
}

light beams by animals was automatically recorded (Jones and Naylor, 1970; Wildish, 1970; Alheit and Naylor, 1976). Problems associated with light beam actographs are: the difficulties in producing sufficiently narrow beams to detect very small animals, and the fact that the light beams may themselves influence activity. Attempts have been made to overcome the latter problem by passing the light through red filters, because evidence has suggested that crustaceans are insensitive to red light (Fernandez, 1973). Experience has shown however, that many crustaceans will react to red light. Fincham $(1970 ; 1972 ; 1973)$ used infra-red filters in an attempt to produce an undetectable light beam, but the strength, quality and definition of the infra-red light produced in this way are usually low. Cederwall (1979) employed ultra-violet light to detect the activity of Pontoporeia but his actograph was not capable of measuring absolute activity levels.

Small, inexpensive infra-red emitting diodes and detectors have recently become available, which allow the production and detection of a strong, narrow beam of infra-red light. These have been incorporated into an actograph for measuring locomotor activity in small, translucent, aquatic animals with a sensitivity not previously attainable.

Rearing the prawn Palaemon elegans Rathke and the brown shrimp Crangon crangon (L.) from hatching to the juvenile phase, under light/dark cycles with 


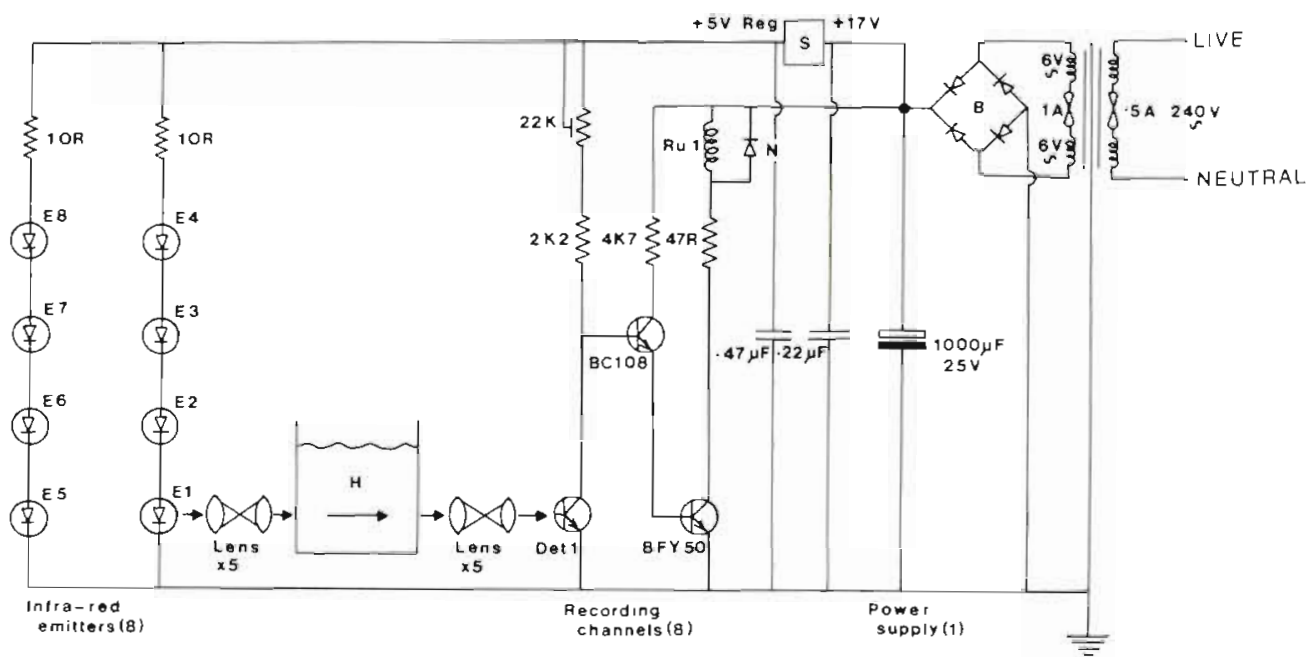

Fig. 1. Circuit diagram of actograph. B: 1-A bridge rectifier R.S. 261-328; Det 1: infra-red detector R.S. 306-083; E 1-8: infrared emitting diode R.S. 306-077; H: recording chamber; lens system incorporates two plastic lenses of $25 \mathrm{~mm}$ diameter (Combined Optical Industries Ltd. $\times 5$ 'Nature Viewer' No 5498, or any simple lens system with a focal length of approximately $5 \mathrm{~cm}$ ); Ru 1: 'Rustrak' coil, $12 \mathrm{~V}$; S: voltage stabilizer Type 7805 R.S.; N: diode IN 4004 . Resistors, all high stability carbon film: 10 R: 10 ohm, 0.5 W; $47 \mathrm{R}: 47 \mathrm{ohm}, 1.0 \mathrm{~W} ; 2 \mathrm{~K} 2: 2.2 \mathrm{Kilo-ohm}, 0.5 \mathrm{~W} ; 4 \mathrm{~K} 7: 4.7$ Kilo-ohm, 0.5 W; $22 \mathrm{~K}: 22 \mathrm{Kilo}-\mathrm{ohm}, 0.25 \mathrm{~W}, 1 \mathrm{n}$ ear present potentiometer. (R.S.: Radio Spares Ltd., London, Catalogue)

non-24 h periods (non-circadian), results in increased mortality, decreased growth rate and changes in morphological development (Dalley, 1979, $1980 \mathrm{a}$, b). It was suggested that the abnormal light regimes prevented the correct synchronization of the various circadian rhythms underlying metabolic processes in the animals. This idea has been further investigated by recording the effect of the non-circadian light regimes on an overt, measurable rhythm in the animals, that of locomotor activity, using the new actograph.

\section{MATERIALS AND METHODS}

The actograph comprises four Perspex recording chambers, each containing $1,800 \mathrm{ml}$ of filtered seawater. The movement of animals in each chamber interrupts two narrow infra-red beams, one passing through the chamber near the bottom and one near the top. Each interruption is registered by an 8-channel 'Rustrak' event recorder. The associated electronic circuit is shown in Figure 1 ; its method of operation is as follows. The infra-red emission, after being first focused into a narrow beam by a lens system, traverses the water in the chamber and is refocused by a second lens system onto an infra-red detector. A pre-set potentiometer is adjusted so that the voltage across the detector and the base of a transistor (BC108, Fig. 1) does not quite allow the transistor to conduct. Any interruption of the beam causes this voltage to rise, the transistor to conduct, a second transistor (BFY50, Fig. 1) to conduct and the Rustrak to register. The electronic circuitry of the actograph is somewhat temp- erature sensitive; therefore, it must be left at the experimental temperature for $2 \mathrm{~h}$ before the potentiometer is adjusted for maximum sensitivity. Where the experimental regime includes a temperature cycle, the electronic circuitry may be isolated from the recording chambers and kept separately at a constant temperature.

It is important that the actograph sides be absolutely parallel, to prevent beam deflection at the Perspex/ seawater interface, and periodically cleaned with surgical spirit to remove grease.

The locomotor activity of specimens of Palaemon elegans and Crangon crangon which had been reared individually or in mass culture under LD 12:12, LD 8:8 or LD Random light/dark cycles (Dalley 1979. $1980 \mathrm{a}$,b), was recorded using the actograph at $20^{\circ} \mathrm{C}$. The specimens of $P$. elegans were $5-7$ months old and $20-35 \mathrm{~mm}$ in total length, and those of $C$. crangon 4-5 months old and 20-35 $\mathrm{mm}$ total length. Activity was recorded of individuals or pairs of animals, firstly for $3-5 \mathrm{~d}$ under the LD regime in which they had been reared, and then in constant darkness (DD) for a further 3-5 $\mathrm{d}$. The water in the actograph was changed before moving the animals to DD. C. crangon was found to require gentle aeration whilst in the actograph, and $2 \mathrm{~cm}$ of clean sand was placed at the bottom of the apparatus for the animals to bury in.

The activity records produced by the actograph for each experimental run, were analysed to give values of either total locomotor activity per hour, or mean locomotor activity per animal per hour. An examination of the data for rhythmicity and the significance of any possibile rhythmicity was made by computer, 

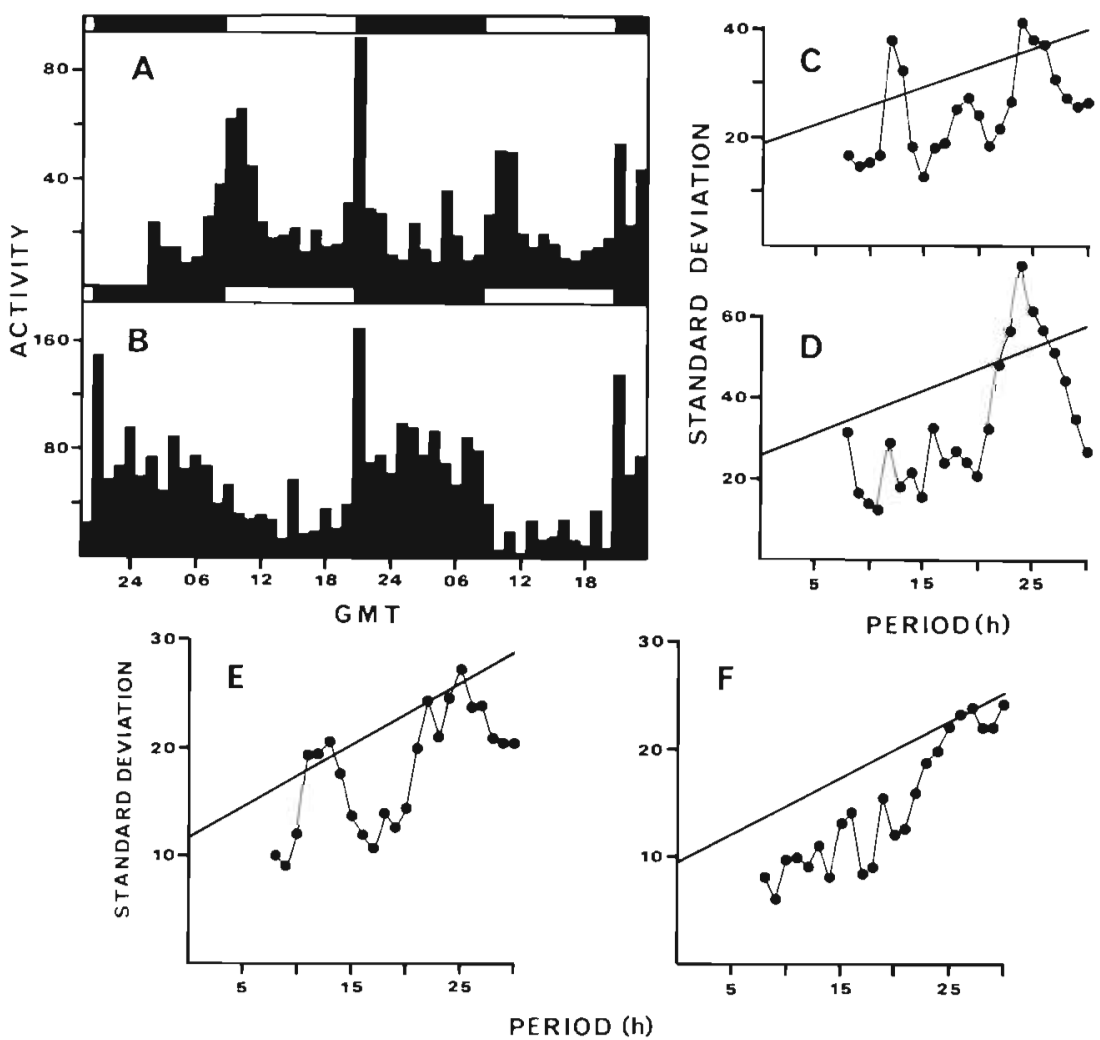

Fig. 2. Palaemon elegans and Crangon crangon reared in LD 12:12. Locomotor activity of (A) P. elegans (n $=4)$, (B) C. crangon (n $=3$ ) in LD 12:12. Periodogram analysis of the data in (A) and (B), respectively (C) and (D). Periodogram analysis of the locomotor activity of (E) P. elegans ( $\mathrm{n}=5$ ), (F) C. crangon $(\mathrm{n}=3$ ) in DD. $\mathrm{n}=$ number of individuals. Upper $95 \%$ confidence limits (shown on each periodogram) derived from linear regression of randomized data of each periodogram and transposed onto original periodogram

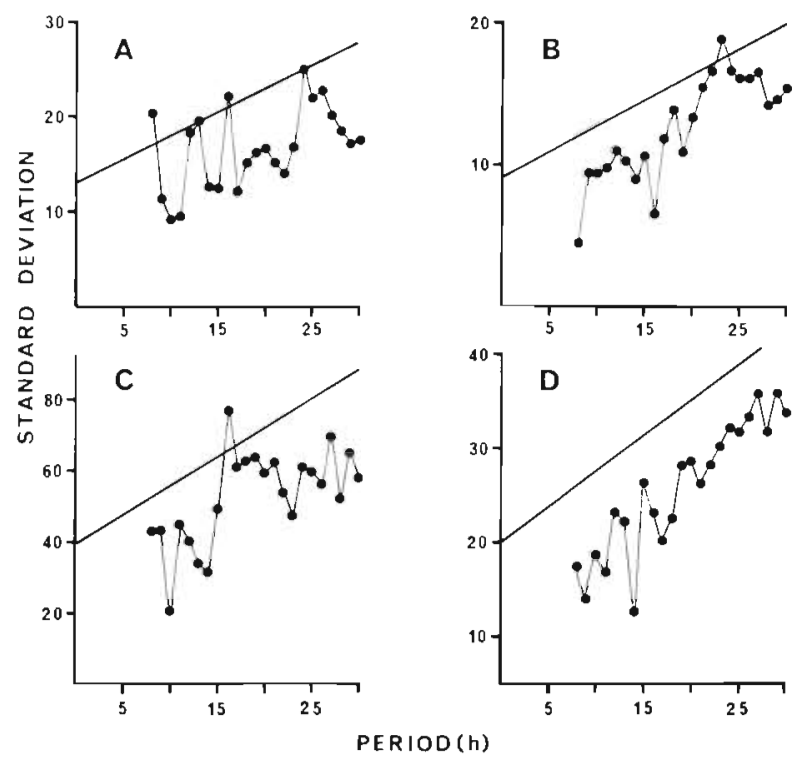

Fig. 3. Palaemon elegans and Crangon crangon reared in LD 8:8. Periodogram analysis of locomotor activity of (A) $P$. elegans $(\mathrm{n}=9),(\mathrm{C})$ C. crangon $(\mathrm{n}=2)$ in LD 8:8. Periodogram analysis of locomotor activity of $(\mathrm{B}) P$. elegans $(\mathrm{n}=4)$, (D) $C$. Crangon ( $\mathrm{n}=4)$ in $\mathrm{DD}$. Confidence limits derived as in Figure 2. $\mathrm{n}=$ number of individuals

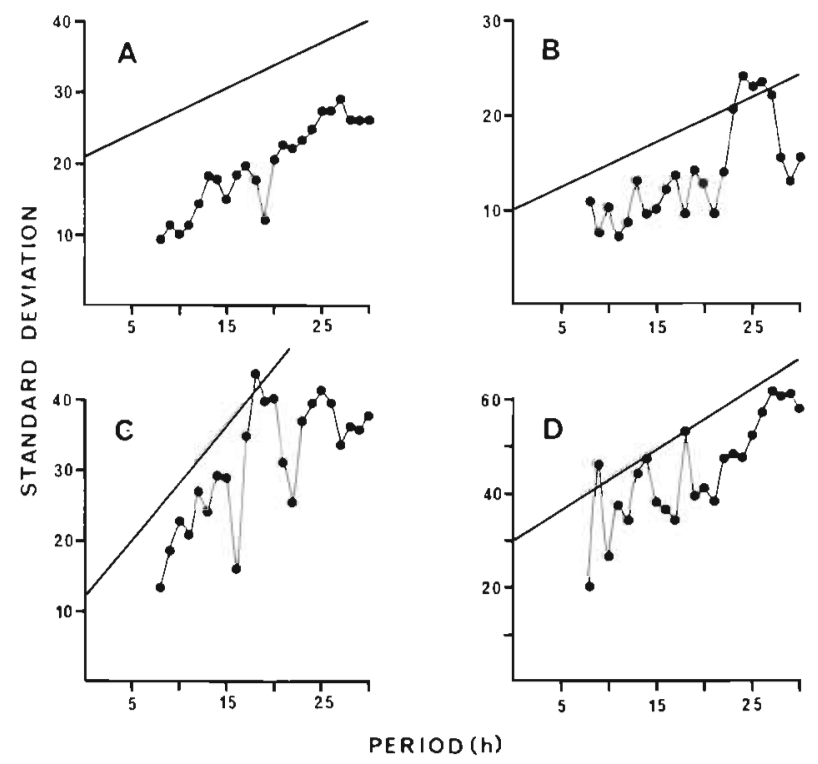

Fig. 4. Palaemon elegans and Crangon crangon reared in LD Random. Periodogram analysis of locomotor activity of (A) $P$. elegans $(\mathrm{n}=4),(\mathrm{C}) C$. crangon $(\mathrm{n}=4)$ in LD Random. Periodogram analysis of locomotor activity of (B) $P$. elegans (n $=4)$, (D) C. crangon $(n=4)$ in DD. Confidence limits derived as in Figure 2. $\mathrm{n}=$ number of individuals 
using a modification of the periodogram analysis of Enright (1965), devised by Williams and Naylor (1978). Here, the standard deviations of 'Buys-Ballot' form estimates for a range of periods from $8-30 \mathrm{~h}$, are plotted against each period tested for. Peaks in the values of the standard deviations reveal the presence of rhythmicity at particular periods. A level of significance for any peaks is assigned by randomizing the data and plotting the 'periodogram' of the randomized data. The regression line with $95 \%$ confidence limits, calculated for this periodogram is then transposed onto the original periodogram and any peaks which fall above the higher $95 \%$ confidence limits are taken to be significant.

\section{RESULTS}

\section{The Actograph}

The actograph had a high sensitivity, and was able to detect the movement of a black wire $1.0 \mathrm{~mm}$ in diameter moved quickly through the beam. Some $50 \%$ of the infra-red beam must be interrupted for the actograph to register, therefore each beam must be approximately $2 \mathrm{~mm}$ in diameter. Unfortunately the actograph was not capable of detecting the movement of animals as small as $1.0 \mathrm{~mm}$, but the movement of many animals less than $5 \mathrm{~mm}$ in their greates dimension, for example mature individuals of Daphnia magna, could be recorded. The actograph has been extensively used to record activity in the isopod Eurydice pulchra (Hastings and Naylor, 1980), and the larger juvenile carideans used in the present study were easily detected.

In this actograph each infra-red beam passed through $8.5 \mathrm{~cm}$ of seawater, but this distance can be increased to over $20 \mathrm{~cm}$.

\section{Activity Patterns of Palaemon elegans and Crangon crangon}

Palaemon elegans displayed periods of heightened activity for up to $8 \mathrm{~h}$ after being placed in the actograph; hence activity records during these periods were not included in the results. The patterns of activity shown by both $P$. elegans and C. crangon in a given light regime varied between individuals, possibly because of different individual reactions to the novel environment of the actograph. The general patterns of activity were as follows.

Activity in LD 12:12. Palaemon elegans displayed peaks of activity coincident with experimental dawn and dusk (Fig. $2 \mathrm{~A}$ ) which is reflected in a peak at $12 \mathrm{~h}$ periodicity (and its multiple at $24 \mathrm{~h}$ ) in the periodogram (Fig, 2C). In contrast, Crangon crangon showed a strong rhythm with increased activity during darkness and peaks of activity at experimental dusk (Fig. 2B) which is confirmed by the significant peak only at $24 \mathrm{~h}$ in the periodogram (Fig. 2D). In DD, some $P$. elegans continued to show a weak rhythm with peaks at $12 \mathrm{~h}$ and $24 \mathrm{~h}$ (Fig. $2 \mathrm{E}$ ), but C. crangon did not reveal an endogenous component in the free-running rhythm (Fig. 2F).

Activity in L D $8: 8$. Both Palaemon elegans and Crangon crangon showed some degree of synchronization to this regime. Individuals of $P$. elegans displayed weak peaks of activity at $8 \mathrm{~h}$ periodicity and multiples thereof, associated with light on and light off (Fig. $3 \mathrm{~A}$ ). C. crangon showed increased activity in the dark, with a peak every $16 \mathrm{~h}$ correlated with experimental dusk (Fig. $3 \mathrm{C}$ ). There was no evidence in either species that any rhythmicity imposed on animals in LD 8:8 continued to be expressed in DD (Fig. 3B and D). Remarkably, Figure $3 \mathrm{~B}$ does reveal a weak activity peak of approximately $24 \mathrm{~h}$ periodicity in some individuals of $P$. elegans in DD.

Activity in LD Random. This regime, devised following Dalley (1980a,b), partially imposed its pattern on the activity of both Palaemon elegans and Crangon crangon. Some peaks of activity corresponded to lights on/off, and greatest activity generally occurred during darkness producing random activity patterns (Fig. $4 \mathrm{~A}$ and $\mathrm{C}$ ). Activity in subsequent DD was also generally random (Fig. $4 \mathrm{~B}$ and D), but as after LD 8:8 Palaemon elegans exhibited a significant peak at about $24 \mathrm{~h}$ periodicity on the periodogram, indicating that some individuals at least displayed a freerunning rhythm of circadian periodicity (Fig. 4 B). The single point outside the upper confidence limit at $9 \mathrm{~h}$ periodicity on the periodogram for $C$. crangon in $\mathrm{DD}$ (Fig. 4D) and at $18 \mathrm{~h}$ in LD (Fig. 4C) remain unexplained but are probably coincidental.

\section{DISCUSSION}

The actograph provides an inexpensive and sensitive method of detecting the movements of small, aquatic animals. The infra-red beams employed are not detectable by the animals, and do not therefore interfere with responses to experimental light/dark regimes. The movement of small animals can be detected in a relatively large volume of water in this apparatus, and aeration and water circulation can be provided to further ensure adequate conditions.

The patterns of locomotor activity recorded by the actograph showed that under circadian light/dark regimes both Palaemon elegans and Crangon crangon display a diel locomotor rhythm, which in $P$. elegans has a weak endogenous component (Fig. 2). This find- 
ing confirms previous investigations in the field and laboratory on these species (Hagerman, 1970; Rodriguez and Naylor, 1972; Al-Adhub and Naylor, 1975). The 'natural' diel locomotor rhythms were clearly prevented from being expressed in the non-circadian regimes, where the patterns of activity were either synchronized to the imposed LD cycles or became random (Fig. 3 and 4). The ability of some Palaemon elegans, reared in non-circadian regimes to display approximately $24 \mathrm{~h}$ rhythms of locomotor activity under constant conditions (Fig. 3B and 4B) requires confirmation by more data, with critical control over possible effects of disturbance when prawns are transferred from one regime to another, but it may indicate that the tendency to organize activity with a circadian periodicity is innate in this species.

The interference with the normal expression of the locomotor rhythms in the animals reared under noncircadian regimes, supports the hypothesis that the detrimental effects suffered by these same animals (Dalley, 1979, 1980a,b) were the result of a desynchronization of the circadian rhythms underlying their metabolism. Aschoff (1969) was able to demonstrate conclusively that human subjects exposed to perturbed LD regimes suffer a desynchronization of their metabolic rhythms, by measuring several rhythmic functions simultaneously. In the present work it was only possible to measure a single overt rhythm. However, in similar work on the blow-fly, Von St. Paul and Aschoff (1978) discussed how disruption in a locomotor rhythm may indicate disruption in the circadian system as a whole. For example, in cases where the locomotor activity failed to entrain to the noncircadian regime, other circadian rhythms in the animal might be expected to free-run, each with slightly different period lengths, and so eventually become desynchronized. Alternatively, since the ability of various metabolic rhythms to entrain to abnormal period lengths is known to differ within individuals (Lobban, 1960) even if one overt rhythm such as locomotor activity entrains to a noncircadian regime, it is unlikely that every rhythm would entrain to period lengths as far removed from $24 \mathrm{~h}$ as those in the present experiments, and internal desynchronization would again result.

Acknowledgements. The authors are grateful to Professor E. Naylor for his advice in preparing the manuscript, and to $\mathrm{Dr}$. J. A. Williams and Dr. M. H. Hastings for help with the computer analysis of the data. The work was supported by the Natural Environment Research Council.

\section{LITERATURE CITED}

Al-Adhub, A. H. Y., Naylor, E. (1975). Emergence rhythms and tidal migrations in the brown shrimp Crangon crangon (L.). J. mar. biol. Ass. UK 55: 801-810
Alheit, J. E., Naylor, E. (1976). Behavioural basis of intertidal zonation in Eurydice pulchra Leach. J. exp. mar. Biol. Ecol. 23: 135-144

Aschoff, J. (1969). Desynchronization and resynchronization of human circadian rhythms. Aerospace Med. 40: $844-849$

Banse, K. (1964). On the vertical distribution of zooplankton in the sea. In: Sears, M. (ed.) Progress in oceanography, Vol. 2. Pergamon Press, Oxford, pp. 53-125

Cederwall, H. (1979). Diurnal oxygen consumption and activity of two Pontoporeia (Amphipoda, Crustacea) species. In: Naylor, E., Hartnoll, R. G. (eds) Cyclic phenomena in marine plants and animals (Proceedings of 13th European Marine Biological Symposium). Pergamon Press, Oxford, pp. $309-316$

Dalley, R. (1979). Effects of non-circadian light cycles on the survival and development of Palaemon elegans Rathke reared in the laboratory. In: Naylor, E., Hartnoll, R. G. (eds) Cyclic phenomena in marine plants and animals (Proceedings of 13th European Marine Biological Symposium). Pergamon Press, Oxford, pp. 157-163

Dalley, R. (1980a). Effects of non-circadian light/dark cycles on the growth and moulting of Palaemon elegans Rathke reared in the laboratory. Mar. Biol. 56:71-78

Dalley, R. $(1980 \mathrm{~b})$. The survival and development of the shrimp Crangon crangon ( $\left.L_{1}\right)$, reared in the laboratory under noncircadian light/dark cycles. J. exp. mar. Biol. Ecol. 47: $101-112$

Dieleman, J. (1979). Swimming thythms, migration and breeding cycles in the estuarine amphipods Gammarus chevreuxi and Gammarus zaddachi. In: Naylor, E., Hartnoll, R. G. (eds) Cyclic phenomena in marine plants and animals (Proceedings of 13th European Marine Biological Symposium). Pergamon Press, Oxford, pp. 415-422

Enright, J. T. (1963). The tidal rhythm of activity of a sandbeach amphipod. Z. vergl. Physiol. 46: 276-313

Enright, J. T. (1965). The search for rhythmicity in biological time series. J. theoret. Biol. 8: $426-468$

Enright, J. T. (1972). A virtuoso isopod. Circa-lunar rhythms and their tidal fine structure. J. comp. Physiol (A) 77 : $141-162$

Fernandez, H. R. (1973). Spectral sensitivity and visual pigments of the compound eye of the galatheid crab Pleuroncodes planipes. Mar. Biol. 20: 148-153

Fincham, A. A. (1970). Rhythmic behaviour of the intertidal amphipod Bathyporeia pelagica. J. mar. biol. Ass. UK. 50: $1057-1068$

Fincham, A. A. (1972). Rhythmic swimming and rheotropism in the amphipod Marinogammarus marinus (Leach). J. exp. mar. Biol. Ecol. 8: 19-26

Fincham, A. A. (1973). Rhythmic swimming behaviour of the New Zealand sand beach isopod Pseudaega punctata Thomson. J. exp. mar. Biol. Ecol. 11: 229-237

Fish, J. D., Fish, S. (1972). The swimming rhythm of Eurydice pulchra (Leach) and a possible explanation of intertidal migration. J. exp. mar. Biol. Ecol. 8: 195-200

Girisch, H. B., Dennert, H. G. (1975). Simulation experiments on the migration of Gammarus zaddachi and Gammarus chevreuxi. Bijdr. Dierk. 45: 20-38

Hagerman, L. (1970). Locomotor activity patterns of Crangon vulgaris (Fabricius) (Crustacea: Natantia). Ophelia 8: $255-266$

Harris, J. E. (1963). The role of endogenous rhythms in vertical migration. J. mar. biol. Ass. UK. 43: 153-166

Harris, J. E., Wolfe, U. K. (1955). A laboratory study of vertical migration. Proc. R. Soc (B) 144: $329-354$

Hastings, M. H., Naylor, E. (1980). Ontogeny of an endogen- 
ous rhythm in Eurydice pulchra. J. exp. mar. biol. Ecol. 46: $137-145$

Heusner, A. A., Enright, J. T (1966). Long-term activity recording in small aquatic animals. Science, N.Y. 154: $532-533$

Jansson, B. O., Källander, C. (1968). On the diurnal activity of some littoral peracarid crustaceans in the Baltic Sea. J. exp. mar. biol. Ecol. 37: 164-170

Jones, D. A., Naylor, E. (1970). The swimming rhythm of the sand beach isopod Eurydice pulchra. J. exp. mar. biol. Ecol. 4: $188-199$

Klapow, L. A. (1972). Natural and artificial rephasing of a tidal rhythm. J. comp. Physiol. (A) 79: 233-258

Lincoln, R. J. (1970). A laboratory investigation into the effects of hydrostatic pressure on the vertical migration of planktonic crustacea. Mar. Biol. 6: 5-11

Lobban, M. C. (1960). The entrainment of circadian rhythms in man. Cold Spring Harb. Symp. quant. Biol. 25: $325-332$
Morgan, E. (1965). The activity rhythm of the amphipod Corophium volutator (Pallas) and its possible relationship to changes in hydrostatic pressure associated with tides. J. Anim. Ecol. 34: $731-746$

Preece, G. S. (1971). The swimming rhythm of Bathyporeia pilosa (Crustacea: Amphipoda). J. mar. biol. Ass. U.K. 51: $777-791$

Rodriguez, G., Naylor, E. (1972). Behavioural rhythms in littoral prawns. J. mar biol. Ass. U.K. 52: 81-95

Von St. Paul, U., Aschoff, J. (1978). Longevity among blowflies Phormia terraenovae R.D. kept in non-24-hour lightdark cycles. J. comp. Physiol. (A) 127: 191-195

Wildish, D. J. (1970). Locomotory activity rhythms in some littoral Orchestia (Crustacea: Amphipoda). J. mar. biol. Ass. U.K. 50: 241-252

Williams, J. A., Naylor, E. (1978). A procedure for the assessment of significance of rhythmicity in time-series data. Int. J. Chronobiol. 5: 435-444

This paper was presented by Professor E. Naylor; it was accepted for printing on November 12, 1980 